\section{Molecular Analysis for Conservation of Georgia Plume, a Threatened Endemic, Using Random Amplified Polymorphic DNA}

\author{
Justin A. Porter, Hazel Y. Wetzstein ${ }^{1}$, and David Berle \\ Department of Horticulture, 1111 Miller Plant Science Building, The \\ University of Georgia, Athens, GA 30602
}

\section{Phillip A. Wadl and Robert N. Trigiano}

Department of Entomology and Plant Pathology, 2431 Joe Johnson Drive, 205 Ellington Plant Science Building, The University of Tennessee, Knoxville, TN 37996

Additional index words. Elliottia racemosa, genetic relationships, Jaccard's coefficient, RAPD

\begin{abstract}
Georgia plume, Elliottia racemosa (Ericaceae), is a small tree endemic only to the state of Georgia, where it is listed as a threatened species. Information about genetic relatedness is critical for establishing approaches for safeguarding, reintroduction, and conservation of this rare species. The genetic relationships among and within selected georgia plume populations were evaluated using random amplified polymorphic DNA (RAPD) in conjunction with site visits at which time a census and GPS survey were conducted. Populations ranged from those containing eight to over 1000 individuals with most populations containing few plants (less than 50 individuals). With one exception, small populations with less than 50 individuals had more genetic similarity than populations with greater numbers of plants. Two protected populations containing large numbers of individuals were sampled extensively. Genetic similarity of individuals was not associated with plant proximity within a population. The small number of individuals and geographic isolation characteristic of many populations were associated with high within-population genetic similarity. Conservation priorities should be given to preserving as many different populations as possible to retain the genetic diversity of the species. Whether the narrow genetic variation found in some populations may be contributing to lack of sexual reproduction in the wild is an area for further study.
\end{abstract}

Georgia plume (Elliottia racemosa, Ericaceae) is a beautiful, rare, small tree endemic only to Georgia, where it is listed as a threatened species (Georgia Department of Natural Resources, 2006). It produces spectacular plume-like white inflorescences that are borne in summer. Flowering is protandrous, and anthers dehisce releasing pollen within closed buds before stigmas are receptive (Radcliffe et al., 2010). Reports on the mode of pollination and seed dispersal are lacking. The scarcity of seed production in the wild is illustrated by the fact that fruit of the plant was unknown until the discovery of a single empty capsule in 1903 followed by a 32-year lapse before the first seed was described (Santamour, 1967). The observation that pollen tetrads are aggregated by viscin strands (Radcliffe et al., 2010) suggests that

Received for publication 23 Jan. 2012. Accepted for publication 9 Mar. 2012

We thank Lisa Kruse and Tom Patrick (GA Dept Natural Resources), Henry Mincey (Wildlife Mgt Branch, Fort Stewart) and Martha Joiner (GA Plant Conservation Alliance) for assistance with field collections and populations.

${ }^{1}$ To whom reprint requests should be addressed; e-mail hywetz@uga.edu. pollen may be dispersed by insect pollinators. Poor pollen quality may contribute to lack of seed development in some populations (Radcliffe et al., 2010; Santamour, 1967). Unclear is whether a lack of genetic diversity is limiting reproduction. Confined to the Coastal Plain region, georgia plume was reported in 1978 to occur in only approximately three dozen locations, although exact numbers of individual plants were difficult to determine (Duncan and Duncan, 1978). Recent reassessments of reported historic occurrences indicate that fewer than two dozen populations remain with losses primarily the result of anthropomorphic influences (Porter, 2010).

Georgia plume suffers from reproduction problems in the wild. In recent times, no seedlings have been observed in the wild (Faircloth, 1970). Although plants can flower abundantly in the summer, few fruit are produced. Low to no fruit production has been detected for much of the plant's known history (Elliott, 1821). Georgia plume has been observed to reproduce vegetatively in the wild through root suckers; however, the extent or degree of clonal patch occurrence has not been ascertained. Georgia plume populations are generally small, i.e., usually less than 50 individuals, and are geographically isolated from each other (Porter, 2010). Critical to its conservation is an understanding of how much genetic variation exists in the species.

Genetic diversity was examined among 10 populations of georgia plume using allozyme analyses, and the species was reported to have relatively low diversity when compared with other woody plant species (Godt and Hamrick, 1999). Although useful for studies of genetic relationships, allozymes have several drawbacks. This technique only allows for well-documented genes that encode for soluble proteins to be studied. Also, differences in protein expression can vary between different tissues and within the same tissue of an individual based on its developmental stage or even different stress factors at the time of sampling (Lee et al., 2002). With the advent of DNA methodologies, a number of methods have been developed to evaluate genetic relatedness in species including RAPD (Williams et al., 1990).

RAPD markers can determine relationships among individuals (Gunter et al., 1996; Neuhaus et al., 1993). RAPDs are relatively inexpensive and relatively easy to use for such work; however, they do present limitations, i.e., reproducibility and the dominant nature of the marker. Nonetheless, RAPDs can provide important information in plant conservation programs and have been used in a number of studies of rare plants. Gonzalez-Perez et al. (2009) used RAPD markers to investigate genetic variation in the endangered legume, Anagyris latifolia, that is endemic to the Canary Islands. This species consists of small, isolated populations similar to georgia plume Schiebold et al. (2009) assessed genetic similarity in the rare German endemic, Calamagrostis pseudopurpurea (saxonian reed bent grass), and were able to identify clonality for the species. Also using RAPD markers, Kandedmir et al. (2004) investigated genetic variation in different populations of Pinus brutia (Turkish pine). Information from this study was used to understand genetic variation for use in breeding programs and to help conserve genetic resources of this economically important tree species. Hollman et al. (2005) used this technique to identify putative clones of Agrostis canina (velvet bentgrass).

A recent assessment of previously reported populations of georgia plume indicated that extensive populations have disappeared as a result of habitat losses resulting from agroforestry, agricultural activities, and urbanization

Table 1. Random amplified polymorphic DNA (RAPD) primers used for polymerase chain reaction and the number of amplification products produced

\begin{tabular}{ccc}
\hline $\begin{array}{c}\text { RAPD } \\
\text { primer }\end{array}$ & Sequence $\left(5^{\prime}-3^{\prime}\right)$ & $\begin{array}{c}\text { No. of amplification } \\
\text { products }\end{array}$ \\
\hline 2 & AGACGCGTAG & 7 \\
3 & TGGACCCACA & 3 \\
4 & GTGGCTTCTC & 5 \\
5 & GCGCAGTATC & 8 \\
6 & CCACCGTACT & 6 \\
7 & TCCGGCTGTT & 6 \\
8 & TGTCCCGTTG & 7 \\
11 & CACACGAGAC & 7 \\
12 & CGTACACCAG & 5 \\
\hline
\end{tabular}




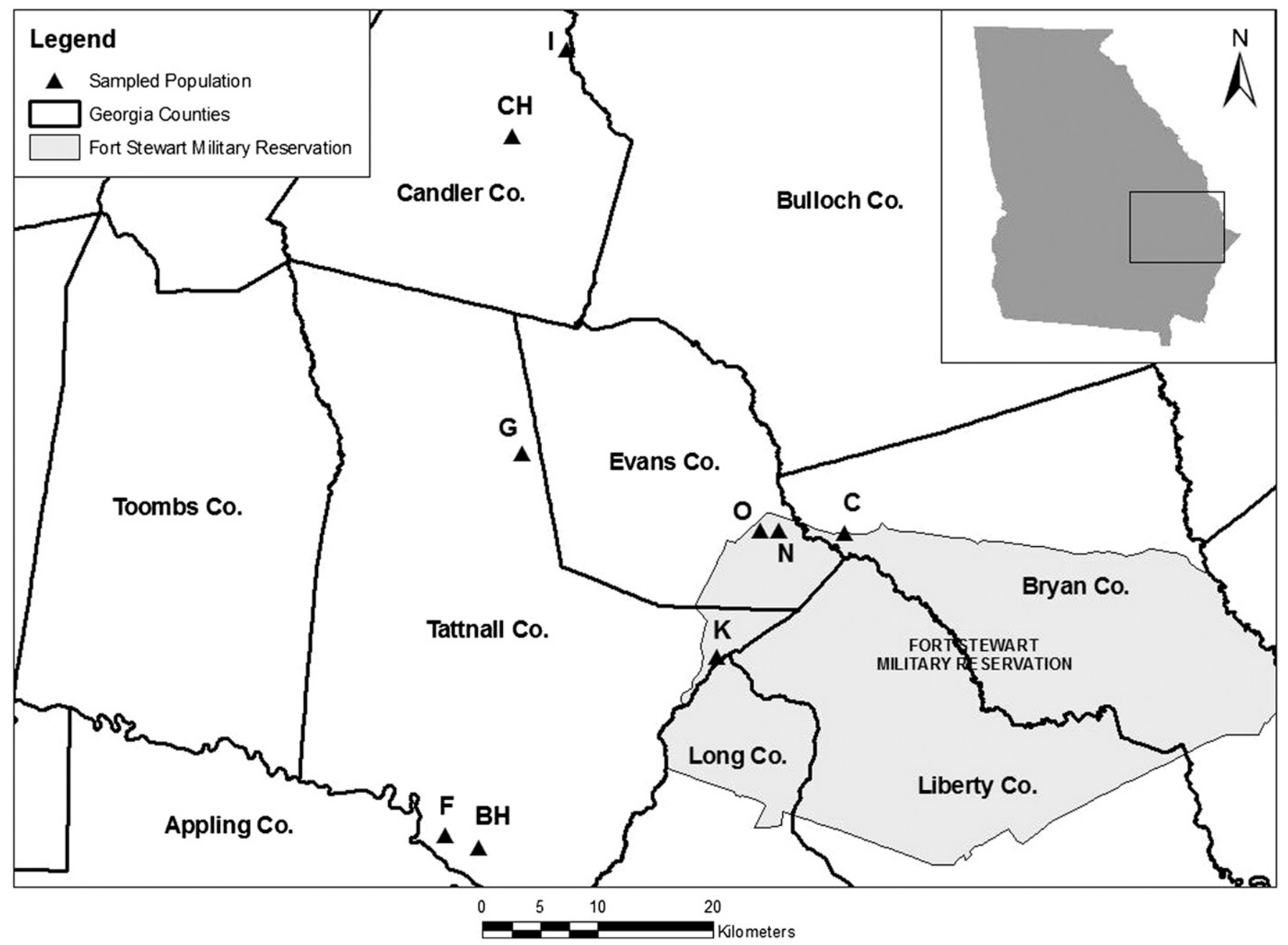

Fig. 1. The locations and counties of georgia plume populations listed in Table 2 and sampled for DNA analyses. Inset shows orientation of the map within the state of Georgia.

(Porter, 2010). Nearly $40 \%$ of the 26 visited populations no longer contained georgia plume and the loss of $58 \%$ of these was likely caused by human activity. Declining population size, decreasing genetic diversity, and habitat fragmentation can lead to reproductive failure and even further losses (Wetzstein and Yi, 2010). Genetic diversity tends to be reduced in small, isolated populations to the point where sexual reproduction may not be possible (Ellstrand and Elam, 1993) in outcrossing plants.

Current work on georgia plume has focused on propagation and safeguarding current populations. A tissue culture protocol has been developed that is effective with mature field-collected material (Woo and Wetzstein, 2008a, 2008b), and field testing of tissue culture-regenerated plants is underway in native habitats (Wetzstein and Yi, 2010). Furthermore, shoot regeneration cultures have been established from 34 genotypes representing 12 populations (Radcliffe et al., 2011). Tissue culture can be an important tool for propagation, safeguarding, and reintroduction of rare and endangered plant species. However, for the effective development of conservation strategies, information on the genetic structure and overall genetic diversity of a species is critical, particularly in species with

Table 2. Location, census of the total number of individuals, and number of plants used for random amplified polymorphic DNA analysis of Elliottia racemosa (georgia plume) populations collected in Georgia.

\begin{tabular}{|c|c|c|c|c|c|}
\hline Population & $\begin{array}{l}\text { County } \\
\text { location }\end{array}$ & $\begin{array}{l}\text { No. of individuals in } \\
\text { the population }\end{array}$ & No. sampled & $\begin{array}{l}\text { Jaccard's } \\
\text { coefficient }^{z}\end{array}$ & $\begin{array}{l}\text { Polymorphic } \\
\text { products (\%) }\end{array}$ \\
\hline $\mathrm{C}$ & Bryan & 8 & 4 & 0.59 & 29 \\
\hline I & Candler & 33 & 4 & 0.86 & 12 \\
\hline $\mathrm{O}$ & Evans & $>1000$ & 4 & 0.59 & 20 \\
\hline $\mathrm{N}$ & Evans & 29 & 4 & 0.81 & 16 \\
\hline G & Tattnall & 42 & 4 & 0.83 & 16 \\
\hline K & Tattnall & 11 & 4 & 0.90 & 6 \\
\hline $\mathrm{F}$ & Tattnall & $\approx 150$ & 4 & 0.69 & 24 \\
\hline $\mathrm{CH}^{\mathrm{y}}$ & Candler & 92 & 62 & 0.38 & 44 \\
\hline $\mathrm{BH}^{\mathrm{x}}$ & Tattnall & $>100$ & 32 & 0.52 & 36 \\
\hline
\end{tabular}

${ }^{2}$ Jaccard's coefficient is a measure of the shared characters or genetic similarity between individual samples in each group.

${ }^{y}$ Charles Harrold Preserve population used for more extensive within population evaluations.

${ }^{\times}$Big Hammock Wildlife Management Area population used for more extensive within-population evaluations.

small and fragmented distributions (Schiebold et al., 2009). Knowledge about plant genetic relationships can assist in identifying areas that should be given priority for conservation (Gonzalez-Perez et al., 2009).

The present study used RAPD markers to evaluate genetic relationships in georgia plume with an objective to determine relationships among and within selected populations. This information is critical for establishing approaches for safeguarding, reintroduction, and conservation of this rare species.

\section{Materials and Methods}

Leaf tissue samples were collected for evaluation from nine populations. A population was defined as a group of individuals that 
had a continuous distribution over a specific area (Li et al., 2008). Georgia plume populations are discrete and disjunct. From each population, samples were randomly collected from four individuals and corresponded to collections made for in vitro propagation studies (Radcliffe et al., 2011). Plants were at least $15 \mathrm{~m}$ apart to decrease the collection of clonal plants produced by root suckers. Two large populations, i.e., Charles Harrold Preserve and Big Hammock Wildlife Management Area (WMA), were more extensively surveyed with collections made from 62 and 33 individuals, respectively. Locations of sampled individuals as well as locations of sampled populations were recorded using GPS. Populations and individuals evaluated corresponded to many of the genotypes established in culture.

Samples consisted of young, not fully expanded leaves. After collection in the field, tissue was placed in a plastic bag with moist paper towels, transported to the laboratory, and then maintained at $-80{ }^{\circ} \mathrm{C}$. DNA was isolated using the DNeasy Mini Plant Kit (Qiagen, Valencia, CA). Extracted DNA was quantified using a NanoDrop ND-1000 spectrophotometer (NanoDrop Technologies, Inc., Wilmington, DE). Samples were diluted to a standard concentration of $1 \mathrm{ng} \cdot \mu \mathrm{L}^{-1}$ for use in a modified RAPD procedure. Polymerase chain reaction (PCR) mixtures (20 $\mu \mathrm{L})$ were slightly modified from the DNA amplification fingerprinting (Caetano-Anollés et al., 1991) procedure used by Wadl et al. (2008) and consisted of $2 \mu \mathrm{L}$ DNA at 1 ng. $\mu \mathrm{L}^{-1}, 2 \mu \mathrm{L} 10 \times$ Stoffel buffer, $2 \mu \mathrm{L}$ of 25 $\mathrm{mm} \mathrm{MgCl} 2,2 \mu \mathrm{L}$ of $2 \mathrm{~mm}$ dNTPs, $2 \mu \mathrm{L}$ of 30 $\mu \mathrm{M}$ primer (Table 1 ), $4 \mathrm{U}$ of Stoffel fragment DNA polymerase, and $9.6 \mu \mathrm{L}$ water. The PCR temperature program was as follows: initial denaturization at $95^{\circ} \mathrm{C}$ for $2 \mathrm{~min}$ : 35 cycles of $95^{\circ} \mathrm{C}$ for $30 \mathrm{~s}, 30{ }^{\circ} \mathrm{C}$ for $30 \mathrm{~s}$, and $72{ }^{\circ} \mathrm{C}$ for 30 $\mathrm{s}$ and then $72{ }^{\circ} \mathrm{C}$ for $2 \mathrm{~min}$ (Wadl et al., 2008). Amplification products were separated electrophoretically on $1.2 \%$ agarose gels at $100 \mathrm{~V}$ and stained with ethidium bromide. Amplifi-

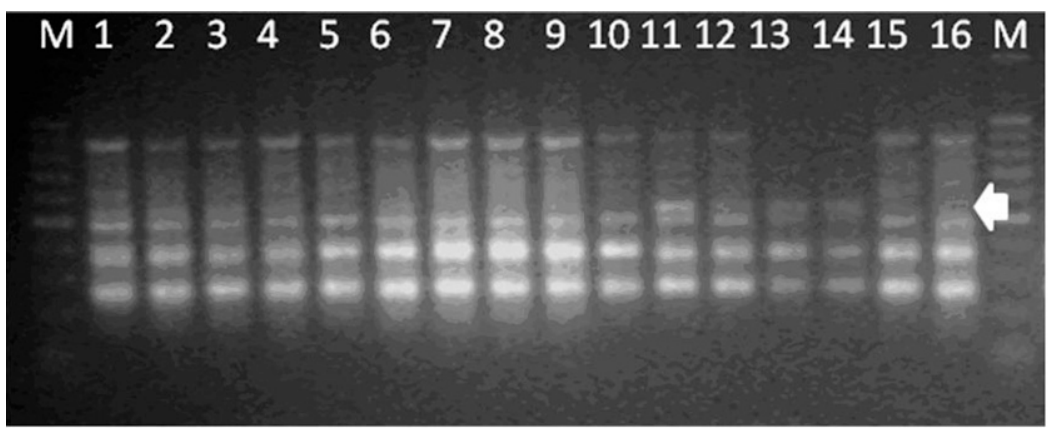

1000

Fig. 2. Amplification of genomic DNA of Elliottia racemosa plants (1-16) located at Big Hammock using random amplified polymorphic DNA primer 5 (GCGCAGTATC). Products were scored as present (1) or absent ( 0$)$ and used to determine relatedness of samples. Arrow indicates polymorphic products at $\approx 500$ bp. $\mathrm{M}=$ molecular marker.

cation products were rated visually as either present (1) or absent (0). Similarity matrices were generated with NTSYSpc Version 2.20q (Applied Biosystems, Carlsbad, CA) based on band scoring. Jaccard's coefficient of similarity was used to show similarity between samples. Cluster analysis using unweighted pair group method with arithmetic mean was used to generate dendrograms that showed similarity relationships among samples.

\section{Results and Discussion}

Relatedness among populations. The counties and locations of the georgia plume populations evaluated in the study are shown in Figure 1. During site visits, a population census at each population was taken to determine the size and extent of populations. The location, census information, and number of plants collected for RAPD markers in each population are shown in Table 2. Amplification with nine RAPD primers resolved a total of 49 products (Table 1). Each primer amplified between three and eight products (Fig. 2).

The dendrogram produced from cluster analysis shows how samples from respective populations are genetically similar in terms of Jaccard's coefficient of similarity (Fig. 3). In some cases, differentiation among populations was high. Some populations contained individuals that clustered with each other indicating high genetic similarity. This was the case in populations $\mathrm{G}, \mathrm{I}, \mathrm{K}$, and $\mathrm{N}$. These populations were geographically small and consisted of less than 50 individuals with a range of 11 to 42 plants (Table 2). These populations separated in the dendrogram at Jaccard's coefficient values of $0.90,0.86$, 0.81 , and 0.83 , respectively, indicating that

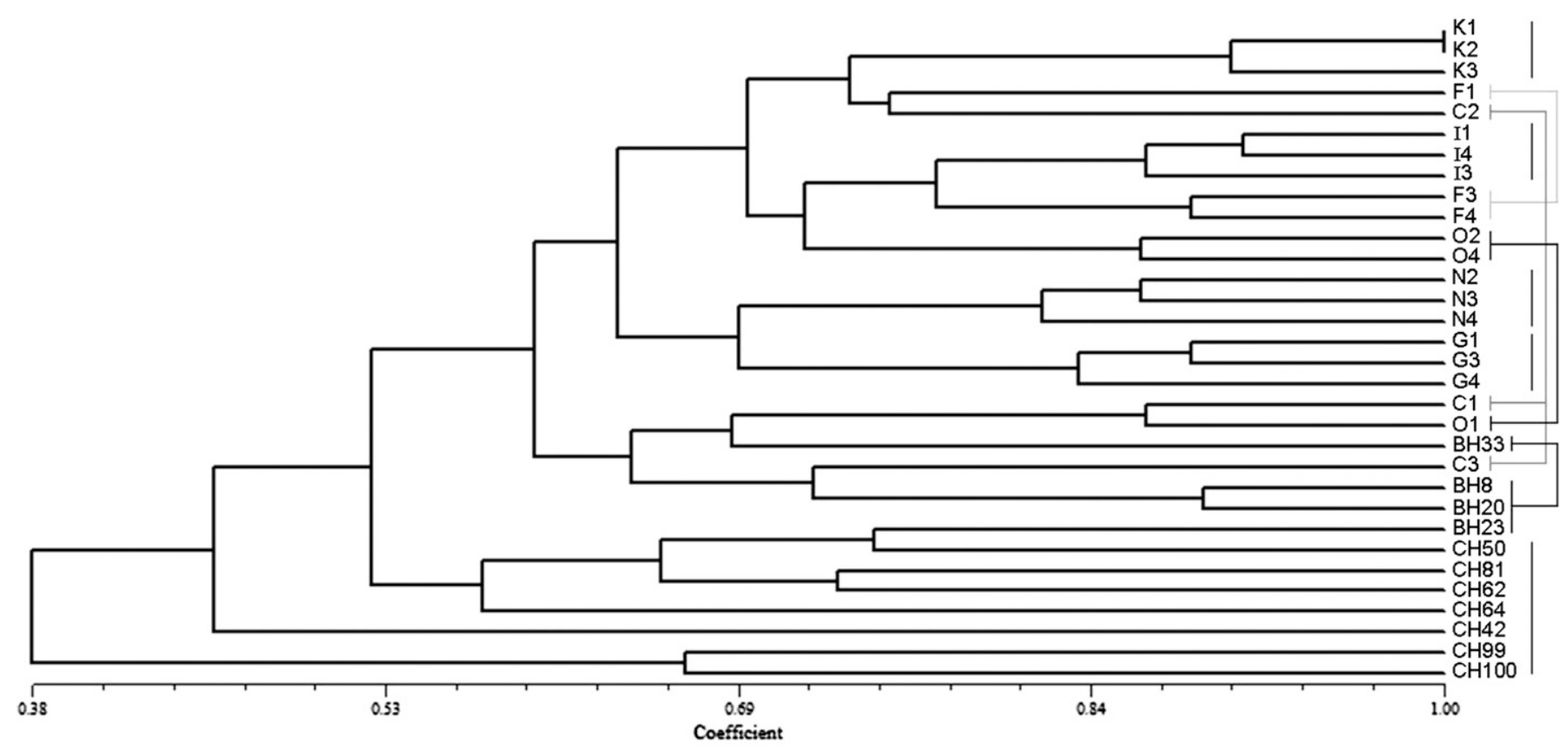

Fig. 3. Dendrogram of genetic relationships between individuals from different georgia plume populations. Letters reflect different populations, whereas numbers reflect individual plants within respective populations. Bars group individual plants from the same populations. Higher coefficient values indicate greater genetic similarity and lower coefficient values indicate less genetic similarity. 
individuals within each of these populations share a large portion of the DNA fragments assayed with other individuals in the same population. As expected, there were fewer polymorphic loci (ranging from $6 \%$ to $16 \%$ ) within these populations (Table 2). Two individuals in population $\mathrm{K}$ (K1 and K2) appear to be clonal illustrating the occurrence of vegetative propagation by root suckers. It should be noted that trees evaluated were at least 15 $\mathrm{m}$ apart to decrease the likelihood of collecting clones. Population $\mathrm{K}$ is composed of only 11 individuals. The extent of clonality at this and other small populations would be of interest to determine.

In georgia plume, the occurrence of small, isolated populations with low genetic diversity may be contributing to the lack of observed sexual reproduction in the wild. In Dictamnus albus, burning bush, population size was directly related to several fitness characteristics such as flower number and fruit size (Henson and Wesche, 2006). Similarly, seed germination was directly related to the size of Silene regia (royal catchfly) populations (Menges, 1991), and seed production was reduced to zero in fragmented and severely reduced populations of Banksia goodii (Good's Banksia) (Lamont et al., 1993). Studies evaluating reproductive fitness in georgia plume and how it relates to population size and genetic similarity are areas for further study.

Low genetic variation within populations has been observed in other species, particularly when propagation in nature is by vegetative means. In a similar study assessing genetic variability with RAPD markers, individual populations of Calamagrostis pseudopurpurea had high genetic similarity
(Schiebold et al., 2009). Diversity was so low that only two genotypes were identified. Seeds produced in these populations were often unviable or failed to germinate; percentages of seed staining positive for viability were between $0 \%$ and $3 \%$. A similar pattern of low seed viability has been observed in many georgia plume populations (Fordham, 1991; Godt and Hamrick, 1999).

In contrast, three populations, $\mathrm{BH}, \mathrm{CH}$, and $\mathrm{O}$, had individuals that did not cluster closely together (Fig. 3). Rather, these populations had plants that grouped near individuals from other populations. These populations separated in the dendrogram at Jaccard's coefficient values of $0.52,0.38$, and 0.59 , respectively, indicating that these individuals shared fewer DNA fragments with individuals within their respective populations than individuals from other populations.
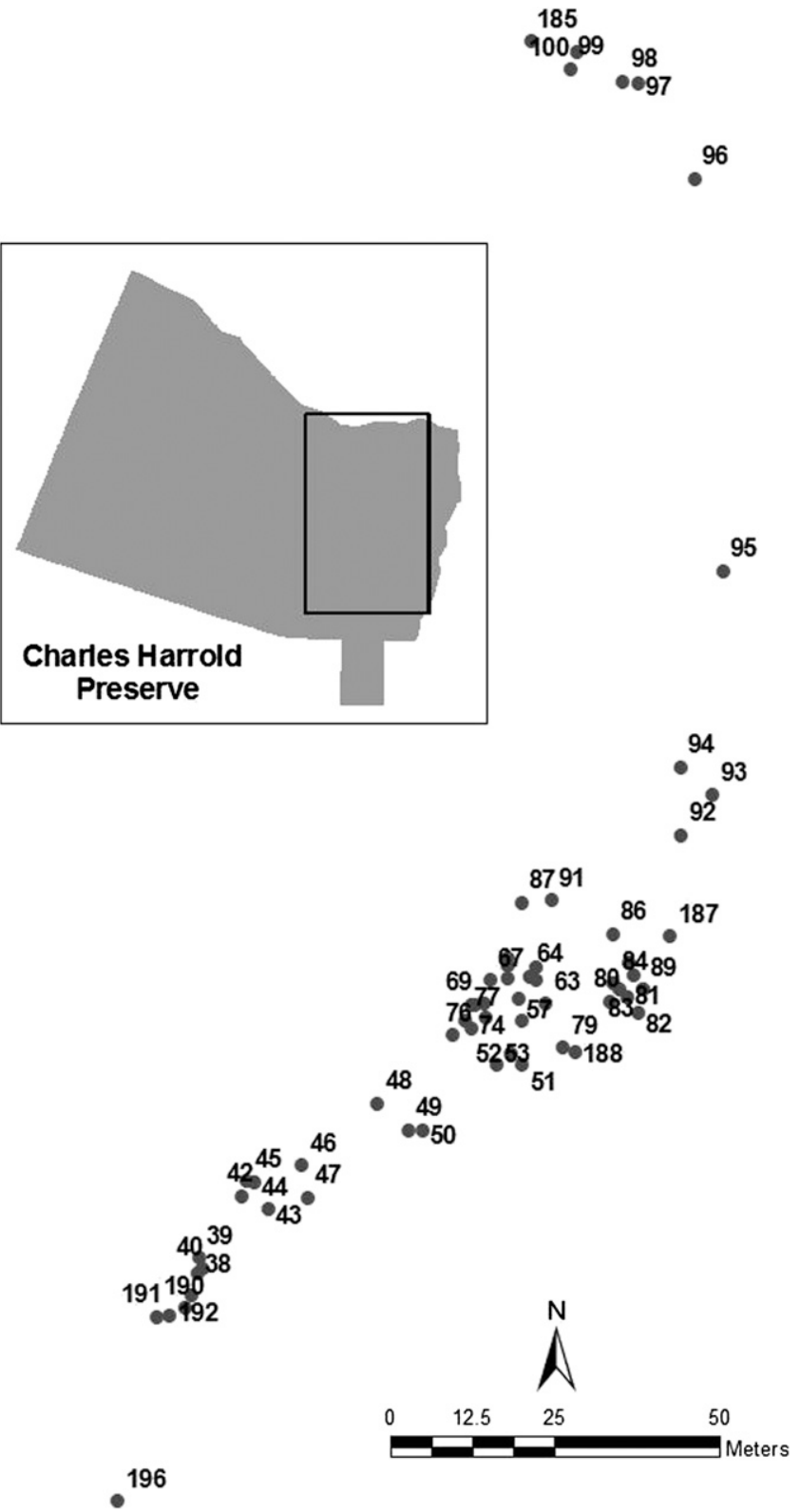

Fig. 4. The location of sampled georgia plume trees from the population located on the eastern part of the 30-ha Charles Harrold Preserve. 
These populations are extensive with total numbers of individuals ranging from 92 to over 1000 (Table 2). Compared with smaller populations, higher numbers of polymorphic bands were amplified, which ranged from $20 \%$ to $44 \%$ (Table 2 ).

Population size did not consistently relate to genetic similarity in all cases. Population $\mathrm{C}$, whose size is limited to only eight individual plants, had a Jaccard's coefficient value of 0.59 that is an intermediate value compared with the other populations evaluated (Fig. 3). In a study focusing on the endangered legume, A. latifolia, higher than expected genetic variation was found in isolated populations (Gonzalez-Perez et al., 2009). The authors concluded that higher amounts of genetic diversity may be an indicator that there were greater numbers of individuals in the past. This could also indicate potentially higher levels of gene flow.

Higher than expected genetic similarity was observed for population $\mathrm{F}$, which had a Jaccard's coefficient value of 0.69 (Fig. 3). Loss of genetic variation can be a consequence of reduction in population size or a result of population fragmentation (Young et al., 1996). It may be that founder effect and/or genetic drift is occurring in small, isolated georgia plume populations. Founder effect is caused when a new population is established from a small subset of a larger, more diverse population. Because anthropogenic disturbances play a role in the current distribution of this species (Porter, 2010), it is likely that small pockets of low diversity have been carved out of a once larger and more diverse population. Therefore, some current populations are likely to be remnant subpopulations of a larger population.

Genetic drift may be occurring as a result of anthropogenic disturbances, which is observed when unique alleles are lost over time as a result of random mating. The result is similar to inbreeding depression in which vigor and fitness are reduced over time. Low genetic diversity in populations of other species has been observed as a result of these processes. Genetic drift reduces genetic variation within small or isolated populations. Although any closed population will undergo genetic drift, it is more pronounced as population size decreases (Ellstrand and Elam, 1993). Founder effect was observed to cause a large reduction of genetic diversity in the aquatic plant Butomus umbellatus (flowering rush) (Kliber and Eckert, 2005).

As suggested by Li et al. (2008) with Gentiana straminea, in some cases, conservation efforts should focus on maintaining as many populations as possible because there are large genetic differences among populations and different populations represent a large amount of genetic variability at the species level. This also appears to be an appropriate conservation strategy for georgia plume. We have conducted a GPS/GIS survey of known georgia plume populations that indicates populations are small with $75 \%$ containing fewer than 50 individuals (Porter, 2010).

Studies on the reproductive biology of georgia plume found that pollen viability is low to moderate with no developmental abnormalities in stigmas or styles (Radcliffe et al., 2010). Plants in the wild are commonly found to flower abundantly but with little or no seed set. Isolated specimens in cultivation have been reported to set viable seed indicating that Georgia plume is not entirely selfincompatible. The current study suggests that the high genetic similarity of individuals within many georgia plume populations may be contributing to the lack of sexual reproduction observed in the wild. Additional studies are needed to ascertain if lack of genetic diversity is limiting reproduction.

Relatedness within populations-Charles Harrold Preserve and Big Hammock. Extensive sampling was conducted at two populations, Charles Harrold Preserve and Big
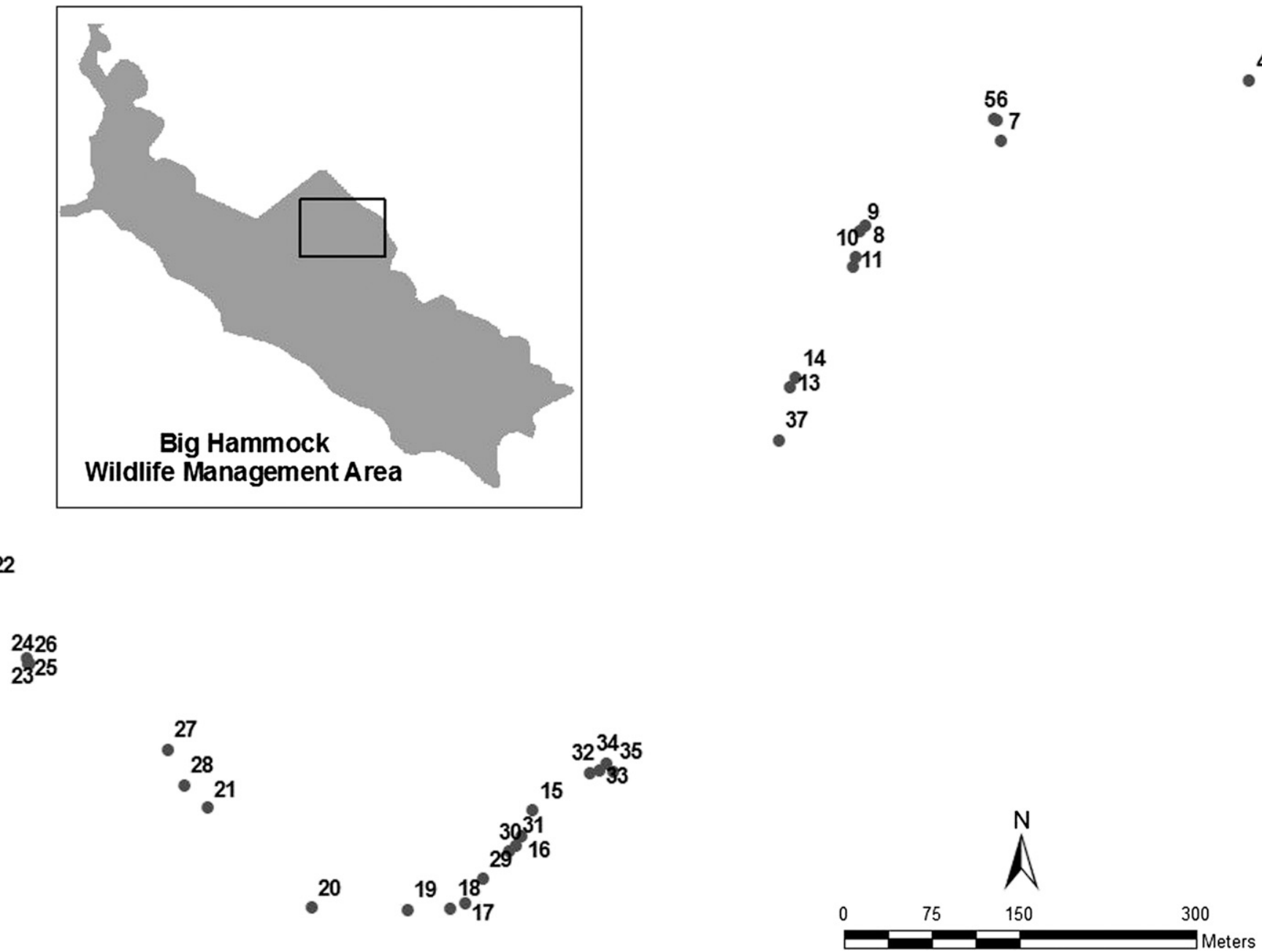

Fig. 5. The location of sampled georgia plume trees from the population located in the Natural Area of the 2500-ha Big Hammock Wildlife Management Area. 
Hammock WMA. These populations represent some of the most extensive georgia plume populations and are under protection by The Nature Conservancy and the Georgia Department of Natural Resources, respectively. The locations of sampled georgia plume trees from the population located on the eastern side of the 30-ha Charles Harrold Preserve are shown in Figure 4. DNA from 62 plants was analyzed from the Charles Harrold Preserve population, which includes $\approx 80 \%$ of all the individuals present at that population. Amplification with nine RAPD primers resolved a total of 49 products, 43 of which $(86 \%)$ showed polymorphisms. Each primer amplified between three and eight products. The location of sampled georgia plume trees from the population located in the Natural Area of the 2500-ha Big Hammock WMA are shown in Figure 5. Thirty-two plants were sampled from this population. Amplification with nine RAPD primers resolved a total of 47 products, 33 of which $(70 \%)$ showed polymorphisms. Each primer amplified between two and eight products.

The evaluation of individual trees in the Charles Harrold Preserve (Fig. 6) and Big Hammock (Fig. 7) populations indicates that individuals within these populations share fewer DNA fragments than individuals in other, smaller populations. In the Charles Harrold population, the Jaccard's coefficient ranged from 0.49 to 0.97 . There was no strong partitioning of genotypes into clusters. Of 49 products, $86 \%$ showed polymorphisms. The Big Hammock population likewise exhibited low genetic similarity with Jaccard's coefficients ranging from 0.56 to 0.95 .

Clustering of individuals within each population did not appear to be related to geographic proximity. For example, in the dendrogram of the Big Hammock population (Fig. 7), individuals with high genetic similarity (i.e., having a Jaccard's coefficient greater than 0.90) were as far apart as $450 \mathrm{~m}$ (Samples 26 and 35) (Fig. 5) or as close as $35 \mathrm{~m}$ (Samples 9 and 10) (Fig. 5). Individuals sharing the most DNA fragments were $215 \mathrm{~m}$ apart for Samples 4 and 5 and $35 \mathrm{~m}$ apart for Samples 9 and 10. Groups of trees that clustered geographically within $20 \mathrm{~m}$ of each other often showed large genetic dissimilarity. In the Charles Harrold Preserve population, the distances between genetically similar individuals ranged from 2 to $12 \mathrm{~m}$ (Figs. 4 and 6). Two clusters in the dendrogram (Samples 38 and 39 and Samples 42 and 45) had individual trees that were within $3 \mathrm{~m}$ of each other. However, trees that were in close proximity frequently exhibited few shared DNA fragments. The geographic extent of the Big Hammock population was expansive and extended over an area of $1100 \times 750 \mathrm{~m}$. Although it contains some of the highest numbers of individuals, the Charles Harrold Preserve population covers a smaller area $(230 \times 135 \mathrm{~m})$ of densely growing individuals (note scale differences in Figs. 4 and 5).

The relative large area and greater number of individual plants at the Charles Harrold and Big Hammock populations compared

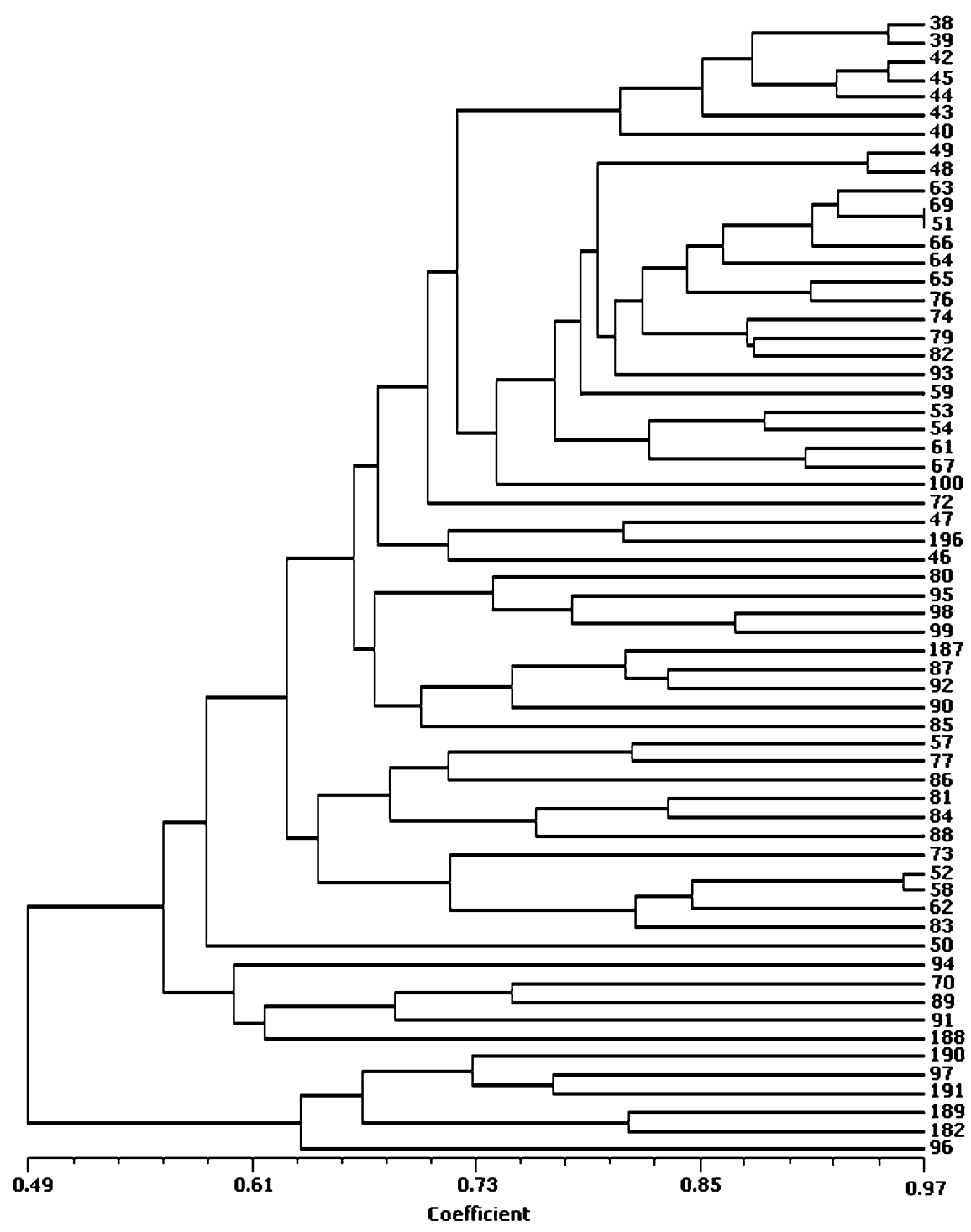

Fig. 6. Dendrogram showing genetic relationships using Jaccard's coefficient of similarity for individual georgia plume plants within the Charles Harrold Preserve population. Higher coefficient values indicate greater genetic similarity and lower coefficient values indicate less genetic similarity.

with other georgia plume populations may account for the higher genetic dissimilarity observed in these populations. Other work studying diversity in relation to population size has generally found a significant positive correlation between these variables. The genetic variation of a population decreased as population size decreased in Salvia pratensis (meadow sage) and Scabiosa columbaria (butterfly blue) (Van Treuren et al., 1991). These species have been noted not only to have declining numbers of populations, but also have fragmented populations that contain both large and small numbers of individuals. These characteristics parallel those observed in georgia plume populations. Populations of Gentiana straminea, endemic to Tibet, are dispersed widely through their range, but individual populations generally contain fewer than 100 individuals. Genetic diversity in these populations as determined by RAPD markers was related to the population size (Li et al., 2008). In the current study, the smaller number of trees analyzed in the smaller populations may have introduced sampling error and is an area for further evaluation.

The current study indicates that many georgia plume populations exhibit high genetic similarity that appears to be related to the characteristically small area and limited number of individuals. Within such populations, individuals tended to group closely together in cluster analysis. This suggests that conservation priorities should be given to preserving as many different populations as possible to preserve the diversity of the species. Small populations can be important in conservation because they may contain unique genetic resources. Genetic variability within populations of georgia plume appears to be related to population size. The Charles Harrold Preserve and Big Hammock populations, two atypically large populations, exhibit relatively extensive genetic dissimilarity. The large amount of potential genetic diversity in the Charles Harrold Preserve and Big Hammock 


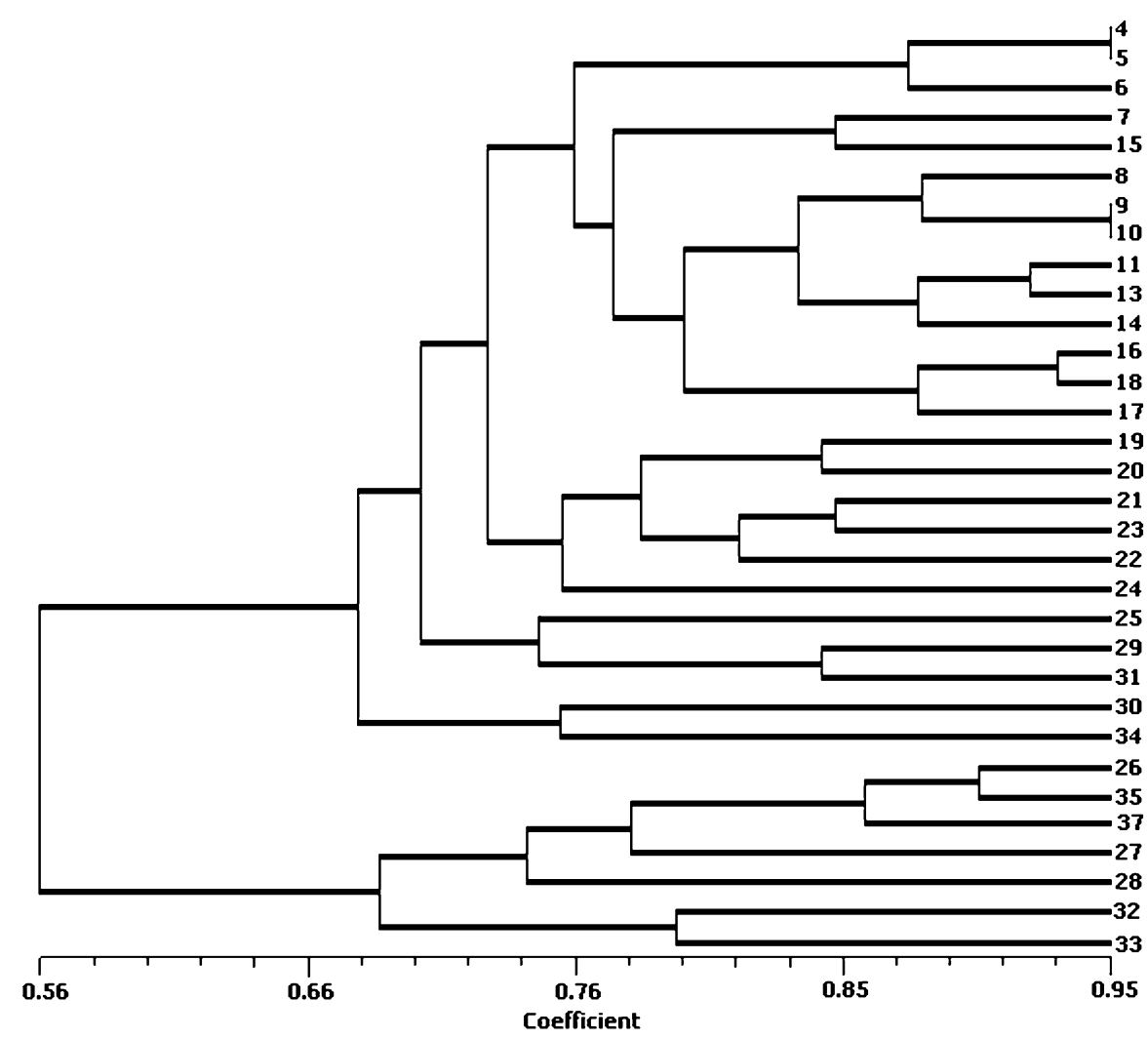

Fig. 7. Dendrogram of genetic relationships using Jaccard's coefficient of similarity for individual georgia plume plants within the Big Hammock Population. Higher coefficient values indicate greater genetic similarity and lower coefficient values indicate less genetic similarity.

populations adds to their importance in conservation efforts.

\section{Literature Cited}

Caetano-Anollés, G., B.J. Bassom, and P.M. Gressoff. 1991. DNA amplification fingerprinting using very short arbitrary oligonucleotide primers. Bio Tech 9:553-557.

Duncan, W.H. and M.B. Duncan. 1978. Elliottia in the piedmont of Georgia. Castanea 43:182-184.

Elliott, S. 1821. A sketch of the botany of South Carolina and Georgia. J.R. Schenck, Charleston, SC.

Ellstrand, N.C. and D.R. Elam. 1993. Population genetic consequences of small population size: Implications for plant conservation. Annu. Rev. Ecol. Syst. 24:217-242.

Faircloth, W.R. 1970. An occurrence of Elliottia in central south Georgia. Castanea 35:58-61.

Fordham, A.J. 1991. Elliottia racemosa and its propagation. Arnoldia 51:59-62.

Georgia Department of Natural Resources. 2006. Georgia's state protected animals and plants. Wildlife Resources Div., Nongame Conservation Section, Social Circle, GA.

Godt, M.J.W. and J.L. Hamrick. 1999. Population genetic analysis of Elliottia racemosa (Ericaceae), a rare Georgia shrub. Mol. Ecol. 8:75-82.

Gonzalez-Perez, M.A., P.A. Sosa, and F.J. Batista. 2009. Genetic variation and conservation of the
White Mountains, California. Amer. J. Bot. 89:566-577.

Li, X.J., H.L. Yang, and J. Liu. 2008. Genetic variation within and between populations of the Qinghai-Tibetan Plateau endemic Gentiana straminea (Gentianaceae) revealed by RAPD markers. Belg. J. Bot. 141:95-102.

Menges, E.S. 1991. Seed germination percentage increases with population size in a fragmented prairie species. Conserv. Biol. 5:158-164.

Neuhaus, D., H. Kühl, J.-G. Kohl, P. Dörfel, and T. Börner. 1993. Investigation on the genetic diversity of Phragmites stands using genomic fingerprinting. Aquat. Bot. 45:357364

Porter, J.A. 2010. Using GIS/GPS as a conservation management tool: Georgia plume as a case study. MS thesis, Univ. Ga., Athens, GA.

Radcliffe, C.A., J.M. Affolter, and H.Y. Wetzstein 2010. Floral morphology and development in Georgia plume, Elliottia racemosa (Ericaceae), a rare coastal plain endemic. J. Amer. Soc. Hort. Sci. 135:487-493.

Radcliffe, C.A., J.M. Affolter, and H.Y. Wetzstein. 2011. In vitro propagation of multiple genotypes of Elliottia racemosa collected from the wild. HortScience 46:287-290.

Santamour, F.S. 1967. Cytology and sterility of Elliottia racemosa. Morris Arboretum Bul. 18:60-63.

Schiebold, S., I. Hensen, K. Wesche, and M. Röser. 2009. Extensive clonality of the endemic Calamagrostis pseudopurpurea Gerstl. ex OR Heine in central Germany revealed by RAPD markers. Plant Biol. 11:473-482.

Van Treuren, R., R. Bijlsma, W. Van Delden, and H.J. Ouborg. 1991. The significance of genetic erosion in the process of extinction. I. Genetic differentiaion in Salvia pratensis and Scabiosa columbaria in relation to population size. Heredity 66:181-189.

Wadl, P.A., X. Wang, A.N. Trigiano, J.A. Skinner, M.T. Windham, R.N. Trigiano, T.A. Rinehart, S.M. Reed, and V.R. Pantalone. 2008. Molecular identification keys for cultivars and lines of Cornus florida and C. kousa based on simple sequence repeat loci. J. Amer. Soc. Hort. Sci. 133:783-793.

Wetzstein, H.Y. and W. Yi. 2010. Tissue culture as a conservation strategy for the safeguarding and reintroduction of Georgia plume. Tipularia 25:2-7.

Williams, J.G.K., A.R. Kubelik, K.J. Livak, J.A. Rafalski, and S.V. Tingey. 1990. DNA polymorphisms amplified by arbitrary primers are useful as genetic markers. Nucleic Acids Res. 18:6531-6535.

Woo, S.M. and H.Y. Wetzstein. 2008a. An efficient tissue culture regeneration system for georgia plume, Elliottia racemosa, a threatened Georgia endemic. HortScience 43:447-453.

Woo, S.M. and H.Y. Wetzstein. 2008b. Morphological and histological evaluations of in vitro regeneration in Elliottia racemosa leaf explants induced on media with thidiazuron. J. Amer. Soc. Hort. Sci. 133:167-172.

Young, A., T. Boyle, and T. Brown. 1996. The population genetic consequences of habitat fragmentation for plants. Trends Ecol. Evol. $11: 413-418$. 